\title{
High water contents in the Jurassic lithospheric mantle of the North China Craton: implications for the destruction of the craton
}

\author{
LU WANG ${ }^{1}$, QUN-KE XIA ${ }^{1 *}$
}

${ }^{1}$ Key Laboratory of Geoscience Big Data and Deep Resource of Zhejiang Province, School of Earth Sciences, Zhejiang University, Hangzhou, 310027, China (*correspondence: qkxia@zju.edu.cn)

There is a consensus that the hydration of the lithospheric mantle was the key factor to weaken the stability of cratonic roots and lead to the final destruction of the North China Craton (NCC). However, when and how the NCC lithospheric mantle was hydrated is still uncertain.

In this study, we conducted whole-rock and mineral geochemical analyses for four middle Jurassic ( 166-152 Ma) basaltic andesites from the eastern NCC. The water content of clinopyroxene (cpx) phenocrysts was measured by Fourier Transform Infrared Spectroscopy (FTIR). Our data support that the basaltic rocks were formed by mixing of the mafic melt derived from the lithospheric mantle and the felsic melt derived from the lower crust. The rims of the reversely-zoned cpx phenocrysts with high $\mathrm{Mg \#} \mathrm{(80-85)} \mathrm{and} \mathrm{Cr}_{2} \mathrm{O}_{3}(0.64-$ $1.07 \mathrm{wt} \%)$ and low $\mathrm{Na}_{2} \mathrm{O}(<0.40 \mathrm{wt} \%)$ are interpreted to represent crystallization from mantle-derived melts although minor differentiation could not be excluded. Based on water contents of these high $\mathrm{Mg \#}$ cpx rims and the cpx/melt partitioning coefficient of water, the calculated water contents for the mantle-derived melts vary from 0.6 to $2.1 \mathrm{wt} \%$. The minimum estimated water contents of the Jurassic lithospheric mantle are 300-1050 ppm, which is comparable with or slightly lower than those of the early Cretaceous lithospheric mantle (571-1214 ppm) during the peak time of the destruction. Our results indicate that the lithospheric mantle of the eastern NCC had already been considerably hydrated in the middle Jurassic, which was probably associated with the flat subduction of the Paleo-Pacific oceanic slab beneath the eastern NCC at that time. 